\title{
PAPER
}

\section{Tourette's syndrome: a cross sectional study to examine the PANDAS hypothesis}

\author{
A J Church, R C Dale, A J Lees, G Giovannoni, M M Robertson
}

J Neurol Neurosurg Psychiatry 2003;74:602-607

See end of article for authors' affiliations

....................

Correspondence to: $\mathrm{Mr}$ Andrew Church

Neuroimmunology Unit Room 917, Institute of Neurology, Queen Square, London WCIN 3BG, UK ; a.church@ion.ucl.ac.uk

Received

21 October 2002

In revised form

13 January 2003

Accepted

20 January 2003
Background: The classical neurological disorder after group A $\beta$ haemolytic streptococcal infection is Sydenham's chorea. Recently a tic disorder occurring after group A streptococcal infection has been described and termed PANDAS (paediatric autoimmune neuropsychiatric disorders associated with streptococcal infection). It is proposed that antibodies induced after group A streptococcal infection react with basal ganglia neurones in Sydenham's chorea and PANDAS. Anti-basal ganglia antibodies (ABGA) are present in most cases of acute Sydenham's chorea, but rarely in controls.

Objective: To investigate the hypothesis that Tourette's syndrome may be associated with group A streptococcal infection and $A B G A$.

Methods: 100 patients with Tourette's syndrome (DSM-IV-TR) were enrolled in a cross sectional study. Children with neurological disease $(n=50)$ and recent uncomplicated streptococcal infection $(n=40)$, adults with neurological disease $(n=50)$, and healthy adults $(n=50)$ were studied as controls. Recent group $A$ streptococcal infection was defined using antistreptolysin $O$ titre (ASOT). ABGA were detected using western immunoblotting and indirect immunofluorescence.

Results: ASOT was raised in $64 \%$ of children with Tourette's syndrome compared with $15 \%$ of paediatric neurological disease controls $(p<0.0001)$, and in $68 \%$ of adults with Tourette's syndrome compared with $12 \%$ of adult neurological controls and $8 \%$ of adult healthy controls $(p<0.05)$. Western immunoblotting showed positive binding in 20\% of children and $27 \%$ of adults with Tourette's syndrome, compared with $2-4 \%$ of control groups $(p<0.05)$. The most common basal ganglia binding was to a $60 \mathrm{kDa}$ antigen, similar to the proposed antigen in Sydenham's chorea. Indirect immunofluorescence revealed autoantibody binding to basal ganglia neurones. Serological evidence of recent group A streptococcal infection, assessed by a raised ASOT, was detected in $91 \%(21 / 23)$ of Tourette's syndrome patients with positive ABGA compared with 57\% (44/77) with negative ABGA $(p<0.01)$.

Conclusions: The results support a role of group A streptococcal infection and basal ganglia autoimmunity in a subgroup of patients with Tourette's syndrome and suggest a pathogenic similarity between Sydenham's chorea and some patients with Tourette's syndrome.
G illes de la Tourette's syndrome is characterised by multiple motor and vocal tics which wax and wane over time. $^{1}$ Epidemiological studies have shown that Tourette's syndrome is relatively common (occurring in up to $1 \%$ of children $)^{2-4}$ and is more prevalent in boys. ${ }^{25}$ The mean age of onset is seven years. ${ }^{5}$ Comorbid neuropsychiatric symptoms are a common feature, and include obsessive-compulsive disorder, attention deficit hyperactivity disorder (ADHD), anxiety, and depression. Indeed, Tourette's syndrome and obsessive-compulsive disorder may be part of the same disease spectrum. ${ }^{15}$

The results from large family studies have suggested that Tourette's syndrome is at least partly genetically determined, although no common single genetic locus has yet been demonstrated. ${ }^{5}$ A multifactorial aetiology has therefore been proposed, with genetic predisposition and environmental factors (such as trauma and infection) playing roles in disease expression. ${ }^{1}$ It is also conceivable that Tourette's syndrome is a heterogeneous disorder, which would confound genetic studies.

It has recently been suggested that group $A \beta$ haemolytic streptococcal infections are an important factor in acute onset neuropsychiatric and movement disorders. ${ }^{6}$ The classic poststreptococcal neurological disorder is Sydenham's chorea, which occurs weeks to months after group A streptococcal infection and is one of the major diagnostic criteria of rheumatic fever. In addition to chorea, patients with Sydenham's chorea also have characteristic behaviour disturbances, particularly emotional lability. ${ }^{7}$ Follow up studies have also shown a high prevalence of obsessive-compulsive disorder in Sydenham's chorea. ${ }^{8}$ Although half the patients with Sydenham's chorea have a self limiting illness, the remaining 50\% will have a chronic course with relapses or persistence. ${ }^{9}$

Until the 1990s, Sydenham's chorea was considered to be the only neurological sequel of streptococcal infection. However, during an outbreak of group A streptococcal infection in Rhode Island, there were many reports of affected children developing sudden onset tics and psychiatric disorders. ${ }^{10}$ Subsequently, the clinical phenotype of poststreptococcal tics and obsessive-compulsive disorder was described, and the term PANDAS (paediatric autoimmune neuropsychiatric disorders associated with streptococcal infections) was coined. ${ }^{6}$ Patients with PANDAS characteristically have exacerbations of characteristic symptoms after further group A streptococcal infections but otherwise have a clinical phenotype similar to Tourette's syndrome. This has led to the hypothesis that Tourette's syndrome may also be related to streptococcal infections, although this association remains

Abbreviations: $A B G A$, anti-basal ganglia antibodies; $A D H D$, attention deficit hyperactivity disorder; ASOT, antistreptolysin O titre; DSM,

Diagnostic and Statistical Manual of Mental Disorders; ICD, International Classification of Diseases; PANDAS, paediatric autoimmune neuropsychiatric disorders associated with streptococcal infection 
Table 1 Demographics of the sample

\begin{tabular}{llll}
\hline Group & $\mathrm{n}$ & $\begin{array}{l}\text { Mean age (years) } \\
\text { (range) }\end{array}$ & Sex (M/F) \\
\hline Child Tourette syndrome & 56 & $12.8(8$ to 17) & $40 / 16$ \\
Adult Tourette syndrome & 44 & $37.8(18$ to 61) & $32 / 12$ \\
Child streptococcal infection & 40 & $9.8(2$ to 15$)$ & $25 / 15$ \\
Child neurological disease & 50 & $7.6(0.5$ to 18$)$ & $24 / 26$ \\
Adult healthy controls & 50 & $35.6(19$ to 57$)$ & $25 / 25$ \\
Adult neurological disease controls & 50 & $41.1(19$ to 70$)$ & $30 / 20$ \\
\hline F, female; M, male. & & &
\end{tabular}

controversial. ${ }^{11}$ The proposed disease mechanism in Sydenham's chorea and PANDAS is cross reactive antibodies induced by group A streptococcal infection that bind specifically to basal ganglia antigens. ${ }^{12}$ The presence of anti-basal ganglia antibodies (ABGA) in Sydenham's chorea ${ }^{13-15}$ and PANDAS ${ }^{10}$ supports this hypothesis.

We aimed to examine the association of streptococcal infection and basal ganglia autoimmunity in Tourette's syndrome by screening for recent streptococcal infection and ABGA in a large cohort of children and adults with this syndrome.

\section{METHODS}

\section{Patients}

Permission for the study was obtained from the local ethics committee of the National Hospital for Neurology and Neurosurgery. Index patients were interviewed by one of us (MMR) using standardised instruments including the National Hospital interview schedule, ${ }^{16}$ the diagnostic interview schedule, ${ }^{17}$ and the Yale global tic severity rating scale. ${ }^{18}$ To be diagnosed as having Tourette's syndrome, patients had to satisfy DSM-IV-TR (APA, 2000) and ICD-10 (WHO, 1992) criteria. Thus they had to have multiple motor and one or more vocal tics, with symptoms lasting longer than a year. Comorbid diagnosis of obsessive-compulsive disorder and ADHD conformed to DSM-IV and ICD-10 criteria.

\section{Controls}

To determine the significance of both streptococcal serology and anti-basal ganglia antibodies, we enrolled controls for comparison (table 1), as follows:

- Children with neurological disease $(\mathrm{n}=50)$. This group contained patients with dystonia $(\mathrm{n}=30)$ of inflammatory $(n=12)$, vascular $(n=6)$, metabolic $(n=6)$, and genetic $(\mathrm{n}=2)$ aetiology. Additional dystonic aetiologies included variant Creutzfeldt-Jakob disease, basal ganglia tumour, athetoid cerebral palsy, and juvenile Parkinson's disease $(\mathrm{n}=1$ each). Also within the neurology control group were patients with invasive viral encephalitis $(\mathrm{n}=20)$.

- Children with recent uncomplicated streptococcal infection ( $\mathrm{n}=40$ ).

- Adults with neurological disease $(\mathrm{n}=50)$, including multiple sclerosis $(n=12)$, dementia $(n=7)$, paraneoplastic syndromes $(n=3)$, autoimmune neuropathy $(n=3)$, acute cerebellitis $(\mathrm{n}=3)$, and other mixed neurological disease.

- Healthy adults from laboratory staff and paediatric hospital workers $(\mathrm{n}=50)$.

The Tourette's syndrome patients and controls were recruited during the same time period and blood samples were stored at $-80^{\circ} \mathrm{C}$ with identification data coded.

\section{Streptococcal serology}

Evidence of recent streptococcal infection was examined using antistreptolysin O titres (ASOT). All patient and control samples were analysed using standardised Dade Behring II nephelometry; an ASOT above $200 \mathrm{IU} / \mathrm{ml}$ is considered to indicate recent infection (WHO guidelines).

\section{Basal ganglia homogenate}

Caudate, putamen, and globus pallidus from a patient with no evidence of neurological disease was kindly provided by the Queen Square brain bank for neurological disorders, Institute of Neurology, London. The block of tissue was homogenised with a small volume of saline containing protease inhibitors (Sigma Chemicals, Poole, Dorset, UK) and centrifuged for 30 minutes at $7500 \times g$. Equal volumes of supernatant and Di-isopropyl ether were mixed and centrifuged at $600 \times g$ for 10 minutes to remove lipid from the supernatant. The protein fraction was then collected and stored at $-80^{\circ} \mathrm{C}$ until required.

\section{Basal ganglia antibody western immunoblotting}

As previously described ${ }^{15}$ the basal ganglia homogenate was mixed with lithium dodecyl sulphate sample buffer (Invitrogen, USA), containing $0.05 \mathrm{M}$ dithiothreitol and heated at $65^{\circ} \mathrm{C}$ for 15 minutes. A total of $30 \mu \mathrm{g}$ of protein was loaded onto a $4-12 \%$ bis-tris gel (Invitrogen, Paisley, Scotland, UK) and electrophoresed. The proteins were blotted onto nitrocellulose (Sartorius, Epsom, Surrey, UK) and blocked with 2\% milk proteins for two hours. Samples were diluted $1 / 300$, applied to the blot, and incubated overnight at $4^{\circ} \mathrm{C}$. The nitrocellulose was washed with 10 changes of $0.9 \%$ saline containing $0.2 \%$ milk proteins and $0.025 \%$ Tween. The blot was incubated for two hours with rabbit anti-human IgG conjugated with horseradish peroxide diluted 1/1000 (Dako, Cambridge, UK). After washing, the substrate 4-chloro-1-naphthol (Sigma) was added and the blot was allowed to develop for 15 minutes. Western immunoblotting was done in all patients and controls.

\section{Basal ganglia antibody indirect immunofluorescence}

Indirect immunofluorescence was undertaken in 10 western immunoblot positive Tourette's syndrome patients and 10 controls from each group. Using previously described methods, ${ }^{13}{ }^{15} 10 \mu \mathrm{m}$ sections of normal human basal ganglia were cut from a snap frozen tissue block of caudate and putamen. Control and patient sera were diluted 1:10 in phosphate buffered saline (PBS), overlaid onto prepared slides, and incubated for 30 minutes. A control slide was also prepared and incubated with PBS alone for 30 minutes to assess background fluorescence. All slides were washed in PBS and incubated with anti-human IgG conjugated with fluorescein isothiocyanate (Dako) and analysed using a fluorescence microscope.

\section{Statistical analysis}

All statistical analyses were done using SAS software (SAS Institute Inc, Cary, North Carolina, USA). Streptococcal serology was compared using the non-parametric two sample exact Wilcoxon rank-sum test. Positive ABGA Western immunoblotting was compared in each subgroup using $\chi^{2}$ tests. Ninety five per cent confidence intervals (CI) are given.

\section{RESULTS}

\section{Demographics}

Demographic data on the patients are summarised in table 1. The serology results were analysed in paediatric and adult 

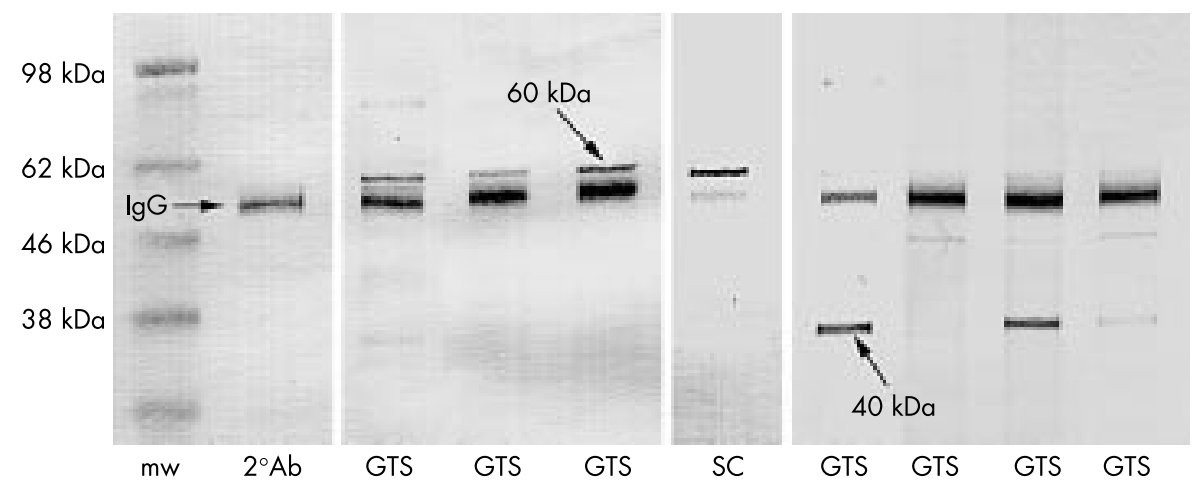

Figure 1 Western immunoblot against homogenate of human basal ganglia. An $\lg G$ band is present in lanes from both patients and controls and is from the human basal ganglia donor. Tourette syndrome patients have an IgG response against a $60 \mathrm{kDa}$ basal ganglia antigen which is similar to the pattern seen in Sydenham's chorea. Other lgG binding is to a $40 \mathrm{kDa}$ and a $45 \mathrm{kDa}$ basal ganglia antigen. mw, molecular weight marker; GTS, Gilles de la Tourette syndrome patients; SC, Sydenham's chorea; $2^{\circ} \mathrm{Ab}$, secondary antibody only.

groups separately, because of the higher incidence of streptococcal infection in childhood. The Tourette's syndrome cohort had a mean (SD) diagnostic confidence index of $64(20) \%$, range $14 \%$ to $100 \%$. The prevalences of obsessive-compulsive disorder and ADHD in the total cohort were $31 \%$ and $43 \%$, respectively. The paediatric Tourette's syndrome patients had a diagnostic confidence index of $64(21) \%$, range $14 \%$ to $100 \%$, a $17 \%$ incidence of obsessive-compulsive disorder, and a $49 \%$ incidence of ADHD. The adult Tourette's syndrome patients had a diagnostic confidence index of $63(20) \%$, range $16 \%$ to $100 \%$, a $51 \%$ incidence of obsessive-compulsive disorder, and a $31 \%$ incidence of ADHD in childhood.

\section{Streptococcal serology Paediatric}

As predicted, ASOT was raised in $80 \%$ of the children with recent streptococcal infection (mean 349 IU/ml (95\% CI, 270 to 427$)$ ). ASOT was also raised in $64 \%$ of the children with Tourette's syndrome (299 IU/ml (262 to 335)) and in 18\% of the children with neurological disease (151 IU/ml (101 to 201)). ASOT was raised in the paediatric Tourette's syndrome cohort compared with the neurological controls $(p<0.0001)$, but not with the streptococcal controls $(\mathrm{p}=0.4)$.

\section{Adult}

ASOT was raised in $68 \%$ of the adults with Tourette's syndrome (mean $298 \mathrm{IU} / \mathrm{ml}$ (95\% CI, 243 to 353 ), in 12\% of the adults with neurological disease ( $140 \mathrm{IU} / \mathrm{ml}$ (92 to 188)), and in $8 \%$ of the healthy adults ( $122 \mathrm{IU} / \mathrm{ml}$ ( 101 to 143$)$ ). ASOT was statistically raised in the adult Tourette's syndrome cohort compared with the neurological controls $(p<0.05)$ and the healthy controls $(\mathrm{p}<0.05)$.

\section{ABGA western immunoblotting Paediatric}

Twenty per cent of the paediatric Tourette's syndrome group (12/56) had positive western immunoblotting, compared with $4 \%$ of the neurological controls $(1 / 50)$ and $2 \%$ of the streptococcal controls (1/40). The difference between the Tourette's syndrome group and both control groups was significant $(\mathrm{p}<0.05$ and $\mathrm{p}<0.05$, respectively $)$. Common bands of reactivity were seen in the Tourette's syndrome group, rather than polyspecific binding. The most common responses were to 60 $\mathrm{kDa}(\mathrm{n}=6), 40 \mathrm{kDa}(\mathrm{n}=4), 45 \mathrm{kDa}(\mathrm{n}=3), 67 \mathrm{kDa}(\mathrm{n}=2)$, $80 \mathrm{kDa}(\mathrm{n}=2)$, and $95 \mathrm{kDa}$ antigens $(\mathrm{n}=1)$ (fig 1$)$. The positive neurological controls bound to a $40 \mathrm{kDa}(\mathrm{n}=1)$ and $43 \mathrm{kDa}(\mathrm{n}=1)$ antigen. The positive streptococcal control bound to a $60 \mathrm{kDa}$ antigen.

\section{Adult}

Twenty seven per cent of the adult Tourette's syndrome group (12/44) had positive western immunoblotting, compared with
$2 \%$ of the neurological controls $(1 / 50)$ and $4 \%$ of the healthy controls $(2 / 50)(p<0.005$ and $p<0.005$, respectively). The common antibody binding was also to $60 \mathrm{kDa}(\mathrm{n}=7), 40 \mathrm{kDa}$ $(\mathrm{n}=5), 45 \mathrm{kDa}(\mathrm{n}=2), 80 \mathrm{kDa}(\mathrm{n}=2), 67 \mathrm{kDa}(\mathrm{n}=1)$, and $98 \mathrm{kDa}$ antigens $(\mathrm{n}=1)$. The positive neurological control bound to a $40 \mathrm{kDa}$ antigen. The positive healthy controls both bound to a $55 \mathrm{kDa}$ antigen. In all paediatric and adult Tourette's syndrome patients the most common basal ganglia autoantigen detected was to a $60 \mathrm{kDa}$ protein $(\mathrm{n}=13)$ and then to a $40 \mathrm{kDa}$ protein $(\mathrm{n}=9)$.

\section{ABGA indirect immunofluorescence}

To define the localisation of antibody binding, we carried out indirect immunofluorescence on 10 Tourette's syndrome patients (five paediatric and five adult) with positive western immunoblotting. All patients had the same binding pattern, with IgG binding to large basal ganglia neurones (fig 2). The
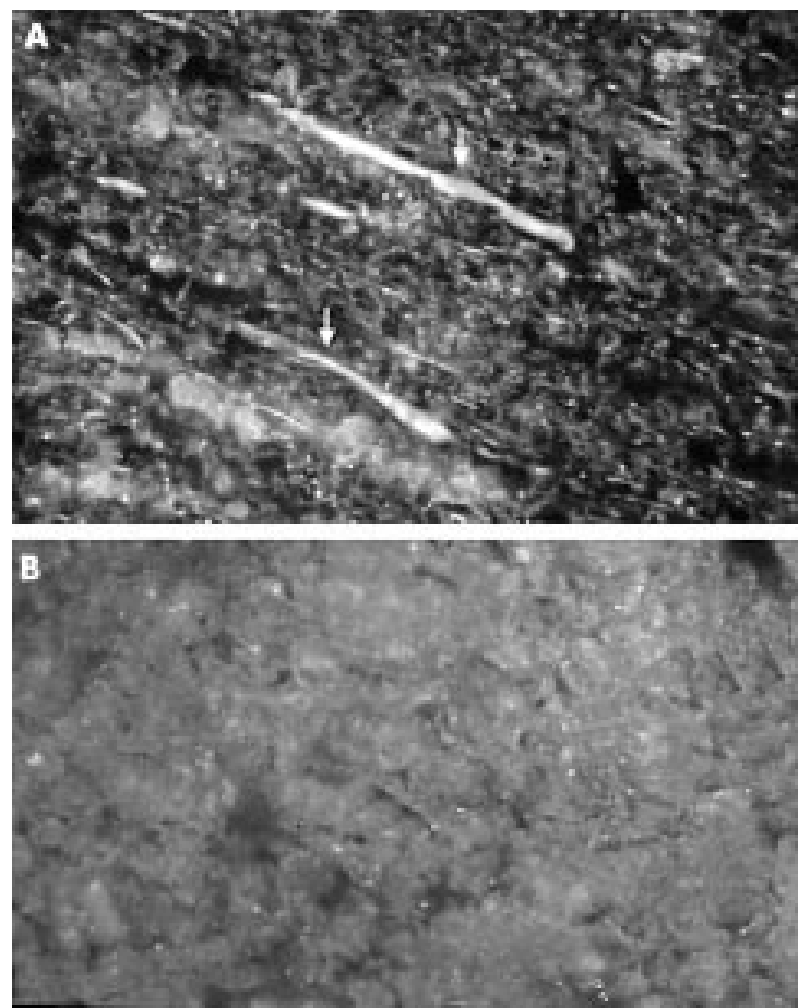

Figure 2 (A) Basal ganglia immunofluorescence revealing antibody binding to basal ganglia neurones in a patient with Tourette's syndrome. (B) Negative binding in control. 
Table 2 Clinical comparisons between $A B G A$ positive and $A B G A$ negative Tourette's syndrome patients*

\begin{tabular}{|c|c|c|c|}
\hline Finding & ABGA positive $(n=24)$ & ABGA negative $(n=77)$ & $\mathrm{p}$ Value \\
\hline Age at first tic (years) (range) & $6.56(2$ to 13$)$ & 6.81 (2 to 16$)$ & NS \\
\hline $\begin{array}{l}\text { Diagnostic confidence index } \\
\text { (mean (SD), [range]) }\end{array}$ & $62(20) \%[36 \%$ to $96 \%]$ & $64(21) \%[14 \%$ to $100 \%]$ & NS \\
\hline $\begin{array}{l}\text { Obsessive-compulsive behaviour } \\
\text { disorder }\end{array}$ & $27 \%$ & $33 \%$ & NS \\
\hline $\begin{array}{l}\text { Attention deficit hyperactivity } \\
\text { disorder }\end{array}$ & $22 \%$ & $50 \%$ & $<0.05$ \\
\hline $\begin{array}{l}\text { History of neuropsychiatric } \\
\text { disease in } 1 \text { st degree family } \\
\text { member } \dagger\end{array}$ & $69.6 \%$ & $753 \%$ & NS \\
\hline ASOT $>200 \mathrm{IU} / \mathrm{ml}$ & $91.3 \%$ & $584 \%$ & $<0.01$ \\
\hline
\end{tabular}

*By western immunoblotting

†Family history of neuropsychiatric disease includes tic disorders, Tourette's syndrome, and obsessive-compulsive disorder.

ABGA, anti-basal ganglia antibodies; ASOT, antistreptolysin $O$ titre.

Table 3 Follow up studies

\begin{tabular}{|c|c|c|c|c|}
\hline Case & Test & 1st Test result & 2nd Test result & $\begin{array}{l}\text { Time after 1st test } \\
\text { (months) }\end{array}$ \\
\hline Case 1 & $\begin{array}{l}\text { ASOT } \\
\text { ABGA }\end{array}$ & $\begin{array}{l}500 \mathrm{IU} / \mathrm{ml} \\
\text { Negative }\end{array}$ & $\begin{array}{l}133 \mathrm{IU} / \mathrm{ml} \\
60 \mathrm{kDa}\end{array}$ & 3 \\
\hline Case 2 & $\begin{array}{l}\text { ASOT } \\
\text { ABGA }\end{array}$ & $\begin{array}{l}260 \mathrm{IU} / \mathrm{ml} \\
\text { Negative }\end{array}$ & $\begin{array}{l}185 \mathrm{IU} / \mathrm{ml} \\
45 \text { and } 60 \mathrm{kDa}\end{array}$ & 3.5 \\
\hline Case 3 & $\begin{array}{l}\text { ASOT } \\
\text { ABGA }\end{array}$ & $\begin{array}{l}710 \mathrm{IU} / \mathrm{ml} \\
\text { Negative }\end{array}$ & $\begin{array}{l}220 \mathrm{lU} / \mathrm{ml} \\
40 \mathrm{kDa}\end{array}$ & 4 \\
\hline Case 4 & $\begin{array}{l}\text { ASOT } \\
\text { ABGA }\end{array}$ & $\begin{array}{l}315 \mathrm{IU} / \mathrm{ml} \\
\text { Negative }\end{array}$ & $\begin{array}{l}<50 \mathrm{IU} / \mathrm{ml} \\
40 \text { and } 95 \mathrm{kDa}\end{array}$ & 3 \\
\hline
\end{tabular}

immunofluorescence staining pattern seen using these Tourette's syndrome patients was identical to that previously described in Sydenham's chorea. ${ }^{15}$ None of the controls tested had reactivity against any cellular component of the basal ganglia.

\section{Raised streptococcal serology and positive ABGA}

Ninety one per cent of Tourette's syndrome patients with positive ABGA western immunoblotting (21/23) had a positive ASOT, compared with $57 \%$ of Tourette's syndrome patients with negative ABGA western immunoblotting (44/77) $(\mathrm{p}<0.01)$.

\section{Clinical comparison between ABGA positive and ABGA negative groups}

The clinical characteristics (obsessive-compulsive disorder/ ADHD and family history of neuropsychiatric disease) did not differ between patients who were ABGA positive or ABGA negative (table 2 ). The numbers of patients with a significantly raised ASOT were greater in the ABGA positive group (91.3\%) than in the ABGA negative group (58.4\%). We were able to retest the blood of four of the Tourette's syndrome patients who had negative ABGA and positive ASOT 3.5 months after first testing. This showed that ASOT levels had decreased to normal in three cases but ABGA had become positive in all four (table 3 ).

\section{DISCUSSION}

The Tourette's syndrome patients were recruited from a dedicated clinic with all patients fulfilling strict diagnostic criteria. The mean age of onset (6.75 years) and the male predominance were consistent with previously published data. ${ }^{15}$ Similarly, $100 \%$ of the patients in this study presented in childhood
$(<18$ years), which is characteristic of Tourette's syndrome. ${ }^{15}$ As longitudinal studies have shown that $50 \%$ of patients will be free of tics by 18 years of age, and tic severity gradually diminishes in adulthood, ${ }^{1}$ it is likely that this cohort of adult patients with Tourette's syndrome represents a severe form of the disease.

The pathogenesis of Tourette's syndrome remains obscure but it is considered to be an inherited neurodevelopmental disorder resulting in disinhibition of the cortico-striatalthalamic-cortical circuitry. ${ }^{1}$ Although various neurotransmitters have been implicated in the pathogenesis of the syndrome, the most favoured hypothesis is that there are subtle abnormalities of the dopaminergic system. ${ }^{19}$ Tourette's syndrome appears to be a familial disorder, with early reports supporting an autosomal dominant inheritance. ${ }^{2021}$ A systematic whole genome screen revealed two regions, $4 \mathrm{q}$ and $8 \mathrm{p}$, with increased lod scores, and these loci might yet reveal susceptibility genes for Tourette's syndrome..$^{22}$ As a genetic basis for Tourette's syndrome has yet to be uncovered, alternative pathological models are being considered, and Tourette's syndrome may turn out to be a heterogeneous disorder. ${ }^{23}$

The recognition that PANDAS may be pathologically related to Sydenham's chorea, along with the clinical similarity of PANDAS and Tourette's syndrome, has led to the notion that Tourette's syndrome may occur as a result of basal ganglia dysfunction secondary to post-streptococcal autoimmunity. ${ }^{24}$ The observation that patients with tic disorders or Tourette's syndrome are more likely to have positive streptococcal serology than control subjects ${ }^{25-27}$ supports this hypothesis, though not all studies have replicated such an association. ${ }^{28}{ }^{29}$ Preliminary analysis of antibody reactivity to streptococcal $M$ proteins has shown raised titres to M12 and M19-but not to M1, M4, and M6-in 25 adult patients with Tourette's 
syndrome compared with 25 control subjects. ${ }^{26}$ This may suggest that only certain strains of group A streptococcal infection could be linked to Tourette's syndrome. This is compatible with observations that other post-streptococcal immune mediated disorders, such as acute rheumatic fever and glomerulonephritis, are also strain specific. ${ }^{30}$

The proposal that Sydenham's chorea and PANDAS occur as the result of an immune mediated insult is supported by the presence of ABGA which bind to basal ganglia neurones. ${ }^{12-14} \mathrm{In}$ a study of patients with Sydenham's chorea, we have recently shown that ABGA were present in all 20 patients (100\%) with acute disease and in $11 / 16$ patients $(69 \%)$ with persistent disease, but in none of a group of 11 healthy controls. ${ }^{15}$ Increased antibody binding to putamen in Tourette's syndrome, and identification of basal ganglia antigens of molecular weights 60,67 , and $83 \mathrm{kDa}$, have been reported.$^{28}$ A further study also suggested that $60 \mathrm{kDa}$ was the most prevalent basal ganglia autoantigen in Tourette's syndrome, although a complex multivariate analysis is required to establish this association. ${ }^{31}$ Preliminary results from another group also suggested that a $60 \mathrm{kDa}$ and an $83 \mathrm{kDa}$ antigen represented the dominant response in patients with tics, Tourette's syndrome, or obsessive-compulsive disorder, ${ }^{32}$ and the same investigators suggested that these antibodies recognised a calpaincalpastatin complex. ${ }^{33}$ In Sydenham's chorea, we have described three dominant basal ganglia autoantigens of molecular weights 40,45 , and $60 \mathrm{kDa} .{ }^{15}$ The consistent finding of a $60 \mathrm{kDa}$ antigen from this study may suggest that the antigen could be important in Sydenham's chorea, PANDAS, and Tourette's syndrome.

Not all of the studies reported have had similar findings to ours. Two studies using a neuroblastoma cell line rather than basal ganglia as the antigen source found no discriminate antibody responses in Tourette's syndrome. ${ }^{27}{ }^{31}$ It would appear from these studies that human or mammalian brain homogenates should be the preferential source of antigen. The methods for detecting antibodies may also influence the results from different studies; enhanced chemiluminescence is a very sensitive method but produces a multitude of responses in western immunoblotting of patients and controls, most of which are of doubtful significance. ${ }^{27-29} 31$ We propose that colorimetric analysis of western blots in this setting is preferable $^{15}$ and improves specificity, although arguably at the cost of reduced sensitivity.

Using the methods described we found a correlation between ABGA and positive ASOT. Serological evidence of recent group A streptococcal infection was detected in $91 \%$ of patients with positive ABGA and in 57\% with negative ABGA. This may suggest that ABGA and recent streptococcal infection are related in some patients. Interestingly the prevalence of raised ASOT in the ABGA negative patients was significantly more common than in the control groups. This finding suggests that post-streptococcal autoimmunity could be important in a larger proportion of patients with Tourette's syndrome. It is possible that ABGA reactivity is be a phenomenon that waxes and wanes with the clinical course. Indeed three of four patients whom we followed up with positive ASOT but negative ABGA had positive ABGA and decreased ASOT three months after the initial sample was taken. A longitudinal study is required to investigate the temporal association between ABGA, streptococcal serology, and clinical course.

An alternative explanation for ABGA in Sydenham's chorea, PANDAS, and Tourette's syndrome is that it occurs as an epiphenomenonon secondary to basal ganglia damage. We believe this is unlikely, for three reasons. First, control patients with inflammatory, metabolic, and ischaemic basal ganglia diseases uncommonly develop these antibodies. Second, in a provocative study by Hallett and coworkers, the microinfusion of sera or IgG from patients with Tourette's syndrome into the striatum of rats induced stereotypes analogous to the involuntary movements seen in Tourette's syndrome, ${ }^{34}$ suggesting that ABGA may play a pathogenic role. Finally, a randomised trial of therapeutic plasma exchange and intravenous immunoglobulin for PANDAS showed a therapeutic response in favour of the treated patients. ${ }^{35}$

\section{Conclusions}

We have shown that a significant proportion of patients with Tourette's syndrome have evidence of recent streptococcal infection and anti-basal ganglia antibodies. The studies published so far on these antibodies have used immunofluorescence, western immunoblotting, and enzyme linked immunosorbent assay methods, which have different sensitivities and specificities. This may help explain the differences between studies in the reported associations between ABGA and disease. Many investigators have proposed that the presence a $60 \mathrm{kDa}$ autoantigen in Sydenham's chorea, PANDAS, and Tourette's syndrome is significant. The identification of this antigen is crucial in determining the pathogenicity of ABGA in post-streptococcal CNS syndromes.

\section{ACKNOWLEDGEMENTS}

AJC is supported by the University of London central research fund and RCD has a training fellowship from Action Research UK and the Barnwood House trust (SF0971). We thank Linda Kilford and the Queen Square Brain Bank for Neurological Disorders, UCL, London for their help. This work was presented at the International Neuroimmunology Conference, Edinburgh, UK, in September 2001, and at the British Paediatric Neurology Association Conference, Newcastle, UK, in January 2002

\section{Authors' affiliations}

A J Church, G Giovannoni, Neuroinflammation Department, Institute of Neurology, Queen Square, London, UK

M M Robertson, Division of Neuropsychiatry, Institute of Neurology

R C Dale, Neurosciences Unit, Institute of Child Health, London, UK

A J Lees, Reta Lila Weston Institute of Neurological Studies, Royal Free

and University College Hospital Medical School, London, UK

Competing interests: none declared

\section{REFERENCES}

1 Jankovic J. Tourette's syndrome. N Engl J Med 2001;345:1 184-92.

2 Kadesjo B, Gillberg C. Tourette's disorder: epidemiology and comorbidity in primary school children. J Am Acad Child Adolesc Psychiatry 2000;39:548-55

3 Hornsey H, Banerjee S, Zeitlin H, et al. The prevalence of Tourette syndrome in 13-14 year-olds in mainstream schools. J Child Psychol Psychiatry 2001;42:1035-9.

4 Kurlan R, McDermott MP, Deeley C, et al. Prevalence of tics in schoolchildren and association with placement in special education. Neurology 2001;57:1383-8.

5 Robertson $M M$. Tourette syndrome, associated conditions and the complexities of treatment. Brain 2000;1 23:425-62.

6 Swedo SE, Leonard HL, Garvey M, et al. Pediatric autoimmune neuropsychiatric disorders associated with streptococcal infections: clinical description of the first 50 cases. Am J Psychiatry 1998; 155:264-71

7 Swedo SE, Leonard HL, Schapiro MB, et al. Sydenham's chorea: physical and psychological symptoms of St Vitus dance. Pediatrics 1993;91:706-13.

8 Swedo SE, Rapoport JL, Cheslow DL, et al. High prevalence of obsessive-compulsive disorder in patients with Sydenham's chorea. Am J Psychiatry 1989;146:246-9.

9 Cardoso F, Vargas AP, Oliveira LD, et al. Persistent Sydenham's chorea. Mov Disord 1999;14:805-7

10 Kiessling LS, Marcotte AC, Culpepper L. Antineuronal antibodies in movement disorders. Pediatrics 1993;92:39-43.

11 Kurlan R. Tourette's syndrome and "PANDAS": will the relation bear out? Pediatric autoimmune neuropsychiatric disorders associated with streptococcal infection. Neurology 1998;50:1530-4.

12 Bronze MS, Dale JB. Epitopes of streptococcal M proteins that evoke antibodies that cross-react with human brain. J Immunol 1993;151:2820-8.

13 Husby G, Van de Rijn I, Zabriskie JB, et al. Antibodies reacting with cytoplasm of subthalamic and caudate nuclei neurons in chorea and acute rheumatic fever. J Exp Med 1976;144:1094-110.

14 Kotby AA, El Badawy N, El Sokkary S, et al. Antineuronal antibodies in rheumatic chorea. Clin Diagn Lab Immunol 1998;5:836-9.

15 Church AJ, Cardoso F, Dale RC, et al. Anti-basal ganglia antibodies in acute and persistent Sydenham's chorea. Neurology 2002;59:227-31. 
16 Robertson MM, Eapen V. The National hospital interview schedule for the assessment of Gilles de la Tourette syndrome. Int J Methods Psychiatr Res 1996;6:203-26.

17 Robertson MM, Baneriee S, Kurlan R, et al. The Tourette syndrome diagnostic confidence index: development and clinical associations. Neurology 1999;53:21

18 Leckman JF, Riddle MA, Hardin MT, et al. The Yale global tic severity scale: initial testing of a clinician-rated scale of tic severity. J Am Acad Child Adolesc Psychiatry 1989;28:566-73.

19 Singer HS. Current issues in Tourette syndrome. Mov Disord 2000;15:1051-63

20 Kurlan R, Behr J, Medved L, et al. Familial Tourette's syndrome: report of a large pedigree and potential for linkage analysis. Neurology 1986;36:772-6

21 Eapen V, Pauls DL, Robertson MM. Evidence for autosomal dominant transmission in Tourette's syndrome. United Kingdom cohort study. $\mathrm{Br} J$ Psychiatry 1993;162:593-6.

22 Tourette Syndrome Association. A complete genome screen in sib pairs affected by Gilles de la Tourette syndrome. Am J Hum Genet 1999;65: 1428-36.

23 Walkup JT, LaBuda MC, Singer HS, et al. Family study and segregation analysis of Tourette syndrome: evidence for a mixed model of inheritance. Am J Hum Genet 1996;59:684-93.

24 Leonard HL, Swedo SE. Paediatric autoimmune neuropsychiatric disorders associated with streptococcal infection (PANDAS). Int J Neuropsychopharmacol 2001;4:191-8.

25 Cardona F, Orefici G. Group A streptococcal infections and tic disorders in an Italian pediatric population. J Pediatr 2001;138:71-5.
26 Muller N, Kroll B, Schwarz MU, et al. Increased titers of antibodies against streptococcal M12 and M19 proteins in patients with Tourette's syndrome. Psychiatry Res 2001;101:187-93

27 Morshed SA, Parveen S, Leckman JF, et al. Antibodies against neural nuclear, cytoskeletal, and streptococcal epitopes in children and adults with Tourette's syndrome, Sydenham's chorea, and autoimmune disorders. Biol Psychiatry 2001;50:566-77.

28 Singer HS, Giuliano JD, Hansen BH, et al. Antibodies against human putamen in children with Tourette syndrome. Neurology 1998;50: 1618-24.

29 Singer HS, Giuliano JD, Hansen BH, et al. Antibodies against a neuron-like (HTB-10 neuroblastoma) cell in children with Tourette syndrome. Biol Psychiatry 1999;46:775-80.

30 Stollerman GH. Rheumatic fever in the 21 st century. Clin Infect Dis 2001;33:806-14

31 Wendlandt JT, Grus FH, Hansen BH, et al. Striatal antibodies in children with Tourette's syndrome: multivariate discriminant analysis of gG repertoires. J Neuroimmunol 2001;119:106-13.

32 Trifiletti RR, Bandele AN. Serum antibodies to specific brain proteins in patients with tics, Tourette's syndrome, or obsessive-compulsive disorder [abstract]. Ann Neurol 2000;48:511-12.

33 Trifiletti RR, Bandele AN. Antibodies to the calpain-calpastatin complex in patients with tics, Tourette syndrome, or obsessive-compulsive disorde [abstract]. Ann Neurol 2000;48:542.

34 Hallett JJ, Harling-Berg CJ, Knopf PM et al. Anti-striatal antibodies in Tourette syndrome cause neuronal dysfunction. I Neuroimmunol 2000;111:195-202.

35 Perlmutter SJ, Leitman SF, Garvey MA, et al. Therapeutic plasma exchange and intravenous immunoglobulin for obsessive-compulsive disorder and tic disorders in childhood. Lancet 1999:354:1153-8.

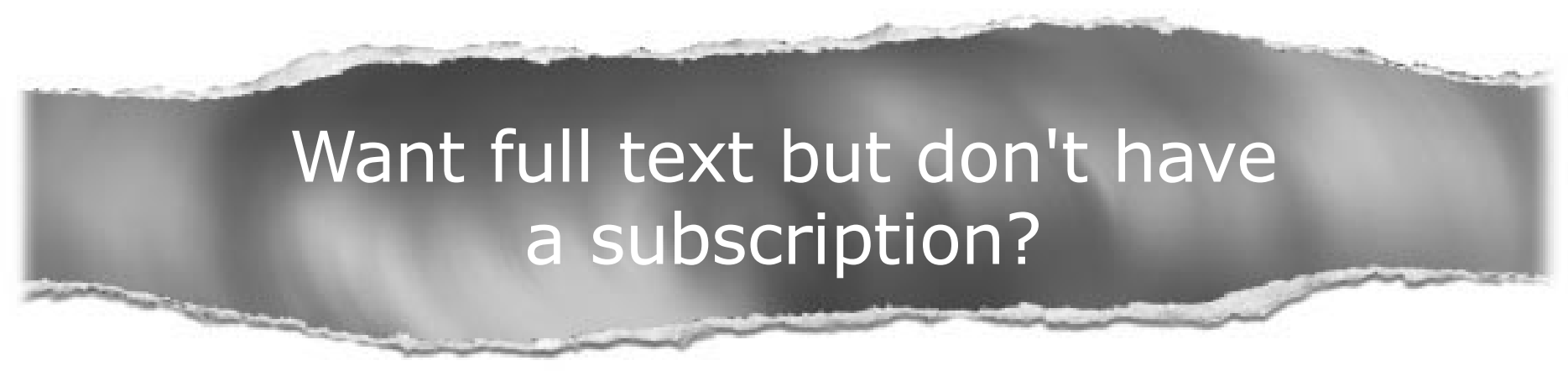

\section{Pay per view}

For just \$8 you can purchase the full text of individual articles using our secure online ordering service. You will have access to the full text of the relevant article for 48 hours during which time you may download and print the pdf file for personal use.

\section{www.jnnp.com}

